\title{
Case Report of Multisystem Inflammatory Syndrome in a Child Related to COVID-19
}

Faisal Ahmed ${ }^{1 *}$

Hasan Zahid'

Moinul Hasan ${ }^{2}$

Anwar Hossain ${ }^{1}$

Md Arman Zaid'

A T M Mahmudur Rahman ${ }^{1}$

J A Siddique ${ }^{1}$

'Department of Paediatrics

Imperial Hospital

Chattogram, Bangladesh.

${ }^{2} \mathrm{COVID}$ Unit and Department of Internal Medicine Imperial Hospital

Chattogram, Bangladesh.
${ }^{*}$ Correspondence to:

Dr. Faisal Ahmed

Consultant

Department of Paediatrics

Imperial Hospital

Chattogram. Bangladesh.

Mobile : +8801993844473

Email : faisalahmed1969@gmail.com

Date of Submission : 25.04 .2021

Date of Acceptance : 05.07 .2021

www.banglajol.info/index.php/CMOSHMCJ

\begin{abstract}
Background : Multisystem Inflammatory Syndrome in Children (MIS-C) is a serious condition that appears to be linked to Coronavirus Disease 2019 (COVID-19). Most children who become infected with the COVID-19 virus have only a mild illness. Aim of this study to evaluate the children who go on to develop MIS-C, some organs and tissues-such as the heart, lungs, blood vessels, kidneys, digestive system, brain, joints, skin or eyes -become severely inflamed.
\end{abstract}

Case Report : 11 years old girl admitted in Paediatric Ward of in Imperial Hospital Chattogram on 12 July 2020 with the complains of fever, loose motion, rash in hands, body and legs, swelling of the wrist and ankle joints which were associated with anorexia, nausea, vomiting and bodyache. For this reason the child was evaluated.

Conclusion : Clinical features in children have varied but predominantly include cardiac dysfunction, abdominal pain, and elevated inflammatory markers, including C-Reactive Protein (CRP) Ferritin, D-dimer and Interleukin-6. MIS-C can lead to shock and multiple organ failure requiring intensive care.

Key words : KD; MIS-C; Pericardial effusion; RT-PCR test; SARS-COVID 19.

\section{INTODUCTION}

SARS-CoV-2 (Severe Acute Respiratory Syndrom-Corona Virus 2) (COVID-19) has been a new challenge to mankind causing a wide range of clinical manifestations, varying from asymptomatic to severe acute respiratory distress syndrome and death. It is thought that paediatric patients exhibit a milder course than adults. The morbidities in paediatric patients have only recently become apparent ${ }^{1}$. New syndrome affecting paediatric patients with COVID-19, Multisystem Inflammatory Syndrome in Children (MIS-C) has been defined by the Centers for Disease Control and Prevention (CDC) and the $\mathrm{WHO}^{2,3}$. The spectrum of MIS-C is characterized by an unopposed inflammatory state that may rapidly progress to multi organ failure. Children with MIS-C present with Persistent Fever (100\%) Conjunctivitis (68\%) Rash (75\%) Elevated inflammatory markers (100\%) Coagulopathy (100\%) Gastrointestinal complaints (85\%) and Cardiac abnormalities $(75 \%)$. The overlap between MIS-C, Kawasaki Disease (KD) and Macrophage activation syndrome suggests that MIS-C represents a spectrum of diseases ${ }^{4}$. The presence of positive SARS-CoV-2 antigen by PCR, serological testing for antibodies or report of close contact with a person diagnosed with COVID-19 helps differentiate MIS-C from other illnesses ${ }^{5}$.

\section{CASE REPORT}

11 years old girl admitted in Paediatric Ward of Imperial Hospital Chattogram on 12 July 2020 with the complains of fever for 10 days, loose motion, rash in hands, body and legs, swelling of the wrist and ankle joints which were associated with anorexia, 
nausea, vomiting and bodyache. For this reason the child was evaluated as "Fever For Investigation" and treated conventionally. The child was found on admission Afebrile, weighing $38 \mathrm{~kg}$, BMI $19.04 \mathrm{~kg} / \mathrm{m}^{2}$. Pulse was $100 \mathrm{~b} \mathrm{pm}$, BP90/60, Spo2 99\% in room air.There were multiple non itchy, non blanchable maculopapular rash in the upper and lower limbs and also in the body. There were painful swelling both wrist and ankle joints. She also had palmer erythema, red lips,raw tongue with red eyes with single palpable cervical lymph node on left side. Other systemic examinations revealed no abnormalities.

The patient did not have any travel history but multiple members of her family had fever few days prior to her illness for which they did not do any SARS-COV2 RT-PCR test. We suspected that the patient suffering from SARS-COV-2 infection and admitted her under COVID unit.

Multiple investigations were done after her admission on $12^{\text {th }}$ July 2020, including CBC, which revealed $\mathrm{Hb} 8.6 \%$, MCV 28.2 fl, MCH 28.9pg, MCHC 33.2 g/dl. Total Leukocyte count was $10.1 \times 10^{9} / \mathrm{L}$. Platelet count was $177 \times 10^{9} / \mathrm{L}$, Serum Ferritin was $1027 \mathrm{ng} / \mathrm{ml}(12$ - 140), IL-6 $175 \mathrm{pg} / \mathrm{ml}(<=7.0)$ CRP $291 \mathrm{mg} / \mathrm{L}(<5.0)$ Procalcitonin $9.5 \mathrm{ng} / \mathrm{m}(<0.05)$ DDimer $3.08 \mathrm{ug} / \mathrm{ml}(<0.50)$ serum creatinine $0.61 \mathrm{mg} / \mathrm{dl}(0.35-$ $0.86) \mathrm{SGPT}$ was $30 \mathrm{IU} / \mathrm{ml}(5-40)$ APTT 27.4s (23.40 - 36.20) PT 14.1s (10.00 - 14.00) serum LDH 246 IU/L $(<250)$. She was also investigated for Dengue, Malaria, Chikungunya and Enteric Fever, which yielded negative results. Her blood culture revealed no growth. ANA, P-ANCA and C-ANCA antibody titre were negative. Her ECG showed sinus tachycardia. High sensitive Troponin-I was 118 ng/L $(<15)$. Chest X-ray showed bilateral homogenous opacity involving the both lower zone.

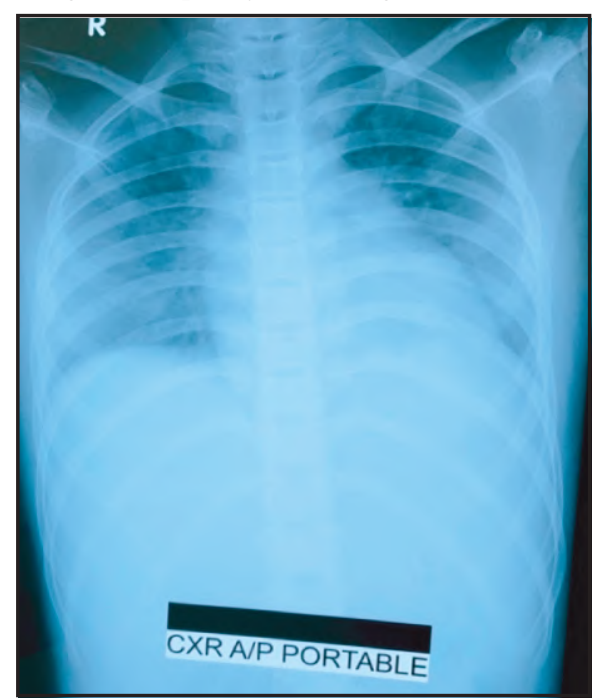

Figure 1 : Chest $\mathrm{X}$ ray AP view: In homogenous Opacity in both lower zone

On Echocardiography, there was mild pericardial effusion (08 $\mathrm{mm}$ in inferior wall and $04 \mathrm{~mm}$ in anterior wall), without any regional motion abnormality and Ejection Fraction was 62\%.

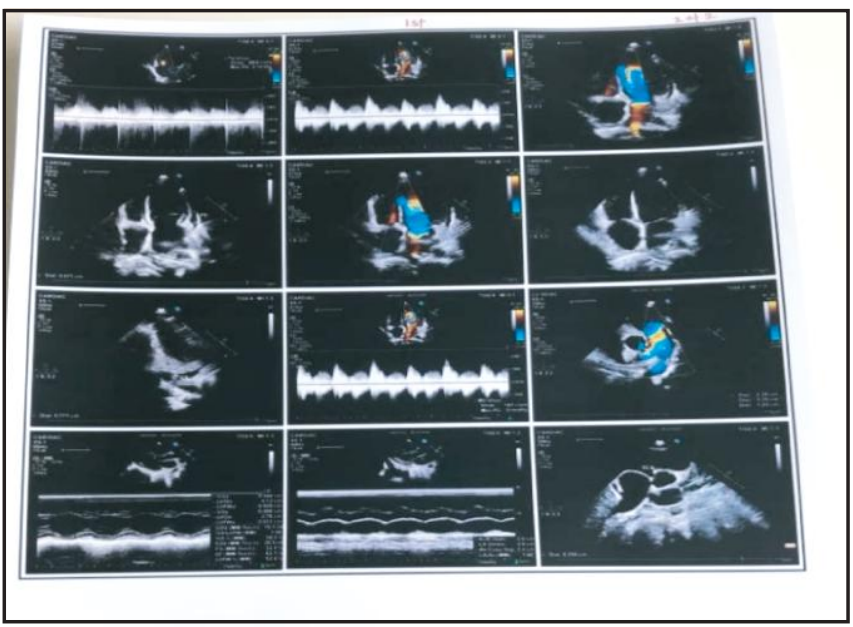

Figure 2 : Echocardiography showing pericardial effusion

Urine R/E revealed no proteinuria and serum albumin was $2.5 \mathrm{~g} / \mathrm{dl}$. Patient's SARS-COV2 RT-PCR test came back negative. The patient was managed with Inj Meropenem and Inj Moxifloxacin along with Methylprednisolone (500mg daily for three days) Heparin (20unit S/C daily) Aspirin (600mg PO 6hrly) and IVIG (Single dose-2 gm/kg) along with other supportive management like Zinc and Vitamin C. On $21^{\text {st }}$ July 2020, CBC was done where $\mathrm{Hb}$ was $10.7 \mathrm{~g} / \mathrm{dl}$, Total Leukocyte count was $5.8 \times 10^{9} / \mathrm{L}$, Platelet count was $545 \times 10^{9} / \mathrm{L}$ with normocytic normochromic blood picture. Serum Ferritin was 243ng/ml, IL-6 - 4.71pg/ml, CRP 10 mg/L, Procalcitonin 0.39 $\mathrm{ng} / \mathrm{ml}$, D-Dimer $0.44 \mathrm{ug} / \mathrm{ml}$, serum creatinine $0.35 \mathrm{mg} / \mathrm{dl}$. SGPT was $21 \mathrm{IU} / \mathrm{ml}$, APTT 33s, PT 13.2s, Troponin-I 35ng/L. Patient's repeat echocardiogram revealed mild pericardial effusion with lesser volume.

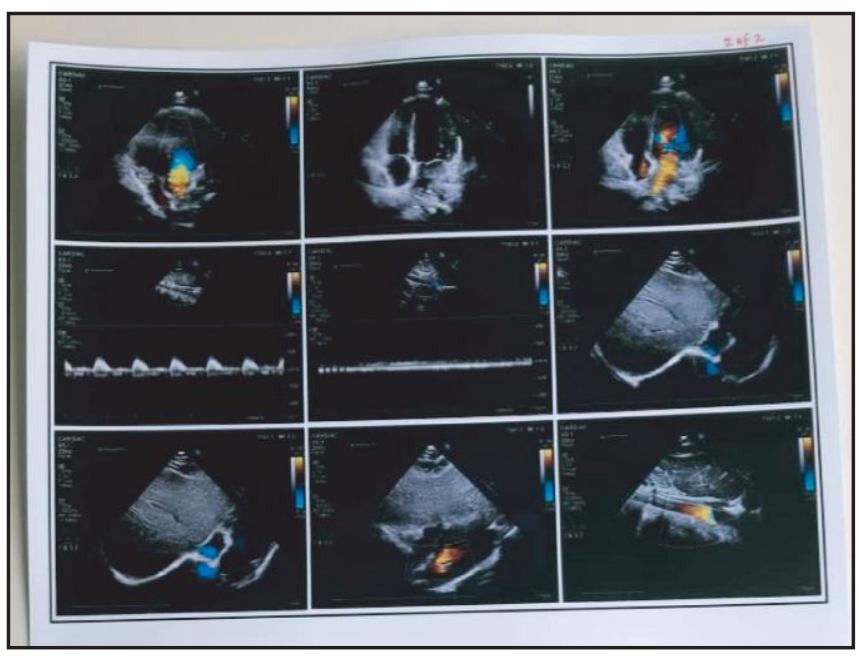

Figure 3 : Follow up Echocardiography showing pericardial effusion in lesser volume.

Patient's generalized wellbeing also significantly improved with the treatment given and she was discharged with Aspirin (300mg PO 6 hrly) for 3 weeks, Tab Prednisolone 40mg PO daily for 10 days along with Iron supplement . 
Comparative change in patients parameter before and after treatment :-

\begin{tabular}{|c|c|}
\hline 12 July 2020 (Before treatment) & $21^{\text {st }}$ July 2020 (After treatment) \\
\hline $\mathrm{Hb}-8.6 \%$, & $\mathrm{Hb}-10.7 \mathrm{~g} / \mathrm{dl}$, \\
\hline Total Leukocyte count $10.1 \times 10^{9} / \mathrm{L}$ & Total Leukocyte count - $5.8 \times 10^{9} / \mathrm{L}$ \\
\hline Platelet count - $177 \times 10^{9} / \mathrm{L}$ & Platelet count - $545 \times 10^{9} / \mathrm{L}$ \\
\hline Serum Ferritin - $1027 \mathrm{ng} / \mathrm{ml}$ (12- 140) & Serum Ferritin - 243ng/ml, \\
\hline IL $-6 \quad-175 \mathrm{pg} / \mathrm{ml}(<=7.0)$ & IL -6 - 4.71pg/ml \\
\hline CRP - $291 \mathrm{mg} / \mathrm{L}(<5.0)$ & $\mathrm{CRP}-10 \mathrm{mg} / \mathrm{L}$ \\
\hline Procalcitonin - $9.5 \mathrm{ng} / \mathrm{ml}(<0.05)$ & Procalcitonin - $0.39 \mathrm{ng} / \mathrm{ml}$ \\
\hline D-Dimer $-3.08 \mathrm{ug} / \mathrm{ml}(<0.50)$ & D-Dimer - $0.44 \mathrm{ug} / \mathrm{ml}$ \\
\hline
\end{tabular}

\section{DISCUSSION}

Multisystem Inflammatory Syndrome in Children (MIS-C) is a serious condition in which some parts of the body such as the heart, blood vessels, kidneys, digestive system, brain, skin or eyes become inflamed. Inflammation typically includes swelling, often with redness and pain. MIS-C included six criteria: serious illness leading to hospitalization, an age of less than 21 years, fever (Body temperature, $>38.0^{\circ} \mathrm{C}$ ) or report of subjective fever lasting at least 24 hours, laboratory evidence of inflammation, multisystem organ involvement (i.e involving at least two systems), and laboratory-confirmed SARS-CoV-2 infection (Positive SARS-CoV-2 Real-time ReverseTranscriptase Polymerase Chain Reaction [RT-PCR] or Antibody test during hospitalization ${ }^{6}$.

Many, but not all, children with MIS-C test negative for a current infection with the virus that causes COVID-19. Yet evidence indicates that many of these children were infected with the COVID-19 virus in the past, as shown by positive Antibody test results ${ }^{2}$. MIS-C shares some of the same signs and symptoms as another condition called Kawasaki disease. Kawasaki disease mainly affects children under 5 years of age. It causes inflammation in the walls of blood vessels, particularly those that supply blood to the heart muscle (Coronary arteries).
On May 14, 2020, the Centers for Disease Control and Prevention (CDC) issued a national health advisory to report on cases meeting the criteria for Multisystem Inflammatory Syndrome in Children (MIS-C) ${ }^{6}$.

In published case series, many of the paediatric patients with this hyper inflammatory syndrome have had fever and mucocutaneous manifestations similar to those of Kawasaki's disease, a rare vasculitis of childhood that can cause coronaryartery aneurysms. 8-14. Some patients have presented with features of Toxic shock syndrome, secondary Hemophagocytic lymphohistiocytosis or Macrophage activation syndrome $\mathrm{e}^{7,8}$. Although the cause of Kawasaki's disease remains unknown, a preceding or active infection has been suspected ${ }^{9,10}$. Like Kawasaki's disease, MIS-C is a syndrome with a range of clinical presentations and an absence of pathognomonic findings or diagnostic tests. Unlike Kawasaki's disease, however, MIS-C has been suggested in early reports to predominantly affect adolescents and children older than 5 years of age and to be associated with more frequent cardiovascular involvement ${ }^{11-13}$.

\section{CONCLUSION}

Clinical features in children have varied but predominantly include cardiac dysfunction, abdominal pain, and elevated inflammatory markers, including C-reactive protein (CRP), Ferritin, D-dimer, and Interleukin-6. MIS-C can lead to shock and multiple organ failure requiring intensive care.

\section{DISCLOSURE}

All the authors declared no competing interest. 


\section{REFERENCES}

1. Castagnoli R,Votto M,Licari A et al. Severe acute respiratory syndrome coronavirus 2 (SARS-CoV-2) infection in children and adolescents: A systematic review. JAMA Pediatr. 2020.

2. Center for Disease Control and Prevention US Department of Health \& Human Services. Multisystem inflammatory syndrome in children (MIS-C) associated with coronavirus disease 2019 (COVID-19). 2020.

https://emergency.cdc.gov/han/2020/han00432.asp [Accessed 20 May 2020].Google Scholar.

3. Freedman SG-C S, Gorman R, Lodha R et al. Multisystem inflammatory syndrome in children and adolescents temporally related to COVID19. 2020.

4. Mahase E. Covid-19: Cases of inflammatory syndrome in children surge after urgent alert. BMJ. 2020;369:m1990. doi:10.1136/bmj.m1990pmid:http://www.ncbi.nlm.nih.gov/pubmed/32414749.

5. Verdoni L, Mazza A, Gervasoni A, et al. An outbreak of severe Kawasaki-like disease at the Italian epicentre of the SARS-CoV-2 epidemic: An observational cohort study. Lancet 2020;395:1771-1778.

doi:10.1016/S0140-6736(20)31103-Xpmid:http://www.ncbi.nlm.nih.gov/pubmed/32410760.

6. Centers for Disease Control and Prevention. Emergency preparedness and response: Multisystem Inflammatory Syndrome in Children (MIS-C) associated with coronavirus disease 2019 (COVID-19). Health advisory. 2020.

7. Crayne C, Cron RQ. Pediatric macrophage activation syndrome, recognizing the tip of the Iceberg.Eur J Rheumatol. 2019;7:Suppl 1:1-8.

8. Wang W, Gong F, Zhu W, Fu S, Zhang Q. Macrophage activation syndrome in Kawasaki disease: More common than we thought? Semin Arthritis Rheum. 2015;44:405-410.

9. Baker AL, Lu M, Minich LL et al. Associated symptoms in the ten days before diagnosis of Kawasaki disease. J Pediatr. 2009;154(4):592.e2595.e2.

10. Benseler SM, McCrindle BW, Silverman ED, Tyrrell PN, Wong J, Yeung RS. Infections and Kawasaki disease: Implications for coronary artery outcome. Pediatrics. 2005;116(6):e760-e766.

11. Shackelford PG, Strauss AW. Kawasaki syndrome. N Engl J Med. 1991;324:1664-1666.

12. Belhadjer Z, Méot M, Bajolle F et al. Acute heart failure in Multisystem Inflammatory Syndrome in Children (MIS-C) in the context of global SARS-CoV-2 pandemic. Circulation 2020 May 17 (Epub ahead of print).

13. Verdoni L, Mazza A, Gervasoni A et al. An outbreak of severe Kawasaki-like disease at the Italian epicentre of the SARS-CoV-2 epidemic: An observational cohort study. Lancet. 2020;395:1771-1778. 